\title{
Comparação de previsões individuais e suas combinações: um estudo com séries industriais
}

\author{
Vera Lúcia Milani Martins ${ }^{\mathrm{a} *}$, Liane Werner \\ a*vlmmartins@yahoo.com.br, UFRGS, Brasil \\ bliane@producao.ufrgs.br, UFRGS, Brasil
}

\begin{abstract}
Resumo
A necessidade de realizar previsões acuradas, oriunda do crescente aprimoramento tecnológico, tem estimulado a aplicação e comparação de diferentes técnicas de modelagem, assim como de métodos de combinação. Historicamente, pesquisadores consideram que combinar previsões originadas de diferentes técnicas melhora a sua acurácia, embora alguns estudos questionem se essa é realmente a melhor opção. Este trabalho procura verificar, para previsões industriais, se há diferença entre a acurácia das previsões individuais e a de suas combinações, por meio da modelagem de séries reais. Como técnicas de previsão individual, utilizam-se a metodologia Box-Jenkins e a modelagem RNA; para a combinação das previsões, utilizam-se os métodos da média aritmética e da variância mínima simplificado. A avaliação de desempenho das previsões é obtida por meio das medidas de acurácia MAPE, MSE e MAE. Como principal resultado, destaca-se a frequência predominante em que previsões obtidas pelo método da variância mínima apresentaram desempenho superior em relação às demais previsões.
\end{abstract}

Palavras-chave

Previsão. Acurácia. Combinação.

\section{Introdução}

A cada dia são apresentadas aos consumidores mais alternativas de escolha entre produtos que apresentam as mesmas características de funcionalidade. Para as empresas fabricantes, esse ambiente gera concorrência cada vez mais acirrada. Tal fato tem estimulado o desenvolvimento e o aprimoramento de técnicas aplicadas à gestão da produção, no intuito de reduzir custos e aumentar a qualidade de seus produtos.

A disponibilidade de opções diversificadas de um mesmo produto ao consumidor permite um aumento do nível de exigência desse consumidor (CLARK; FUJIMOTO, 1991; CLARK; WHEELWRIGHT, 1993). 0 alto nível de qualidade nos produtos já não é mais a única solicitação do mercado, o tempo para a entrega do produto representa uma importante variável no processo da decisão de compra (GILMORE; PINE 11, 2000; ANDERSON-CONNELL; ULRICH; BRANNON, 2002).

Para as empresas de manufatura, a disponibilização imediata de um item ao consumidor envolve uma análise criteriosa do seu processo produtivo. É fundamental manter bem dimensionados os processos envolvidos na cadeia logística. Manter altos estoques representa custos elevados de operacionalização e de oportunidade de capital empatado e, em contrapartida, manter baixos estoques pode incorrer em perda de economia de escala, com altos custos de falta de produtos (GARCIA et al., 2006; WERNER, 2005).

Um dimensionamento de estoques adequado pode ser obtido com conhecimento prévio da demanda futura do mercado. Todavia, não se pode saber com exatidão o que será consumido pelo mercado. 0 uso de informações existentes sobre as necessidades do mercado ou de históricos de demanda possibilitam a realização de previsões.

Fazer previsões é um processo que envolve incerteza. No intuito de minimizá-la, existem diferentes técnicas disponíveis para a sua realização, as quais variam quanto à sua acurácia (exatidão), seu objetivo, seu horizonte de tempo e seus custos (ABRAHAM; 
LEDOLTER, 2005; MAKRIDAKIS; WHEELWRIGHT; HYNDMAN, 1998). As técnicas de previsão de demanda são frequentemente utilizadas para auxiliar no processo de tomada de decisões (SLACK et al., 2007). De tal modo, para se obter a previsão mais adequada torna-se necessário analisar uma gama variada de técnicas e verificar quais fornecem as melhores medidas de acurácia.

As técnicas de previsão podem ser classificadas como quantitativas ou qualitativas. Para a utilização de técnicas de previsão quantitativas é necessária a existência de um registro de dados passados. Tais técnicas de previsão possuem diferentes propriedades, precisão e custos, que devem ser considerados na escolha de um determinado método (MAKRIDAKIS; WHEELWRIGHT; HYNDMAN, 1998).

Conforme Werner (2005), previsões confiáveis podem exigir a utilização de várias técnicas, permitindo captar o maior número de informações disponíveis. Para incorporar diferentes previsões originadas de diferentes técnicas, tem-se utilizado o método conhecido como combinação de previsões.

A combinação de previsões é muitas vezes apresentada como uma alternativa bem-sucedida às técnicas de previsão individuais (HIBON; EVGENIOU, 2005). Estudos apresentam resultados em que as diversas combinações de previsões avaliadas apresentaram acurácia superior à das previsões individuais (CLEMEN, 1989; MAKRIDAKIS; HIBON, 2000; STOCK; WATSON, 2004; PATTON; SHEPPARD, 2009; ANDRAWIS; ATIYA; EL-SHISHINY, 2011; COSTANTINE; PAPPALARDO, 2010).

A estimação dos pesos de cada previsão que compõe a combinação pode incorporar um erro às previsões obtidas, o que caracteriza uma possível desvantagem da combinação em relação às previsões individuais envolvidas (TIMMERMANN, 2006). Na última década, alguns estudos indicam que, sob determinadas condições, as melhores previsões individuais podem apresentar erro menor quando comparadas ao erro médio gerado pela combinação dessas previsões (YANG, 2004; HIBON; EVGENIOU, 2005; TIMMERMANN, 2006).

0 uso ou não das técnicas de combinação de previsões vem sendo questionado em diversas áreas, como turismo e economia (WONG et al., 2007; HOLLAUER; ISSLER; NOTINI, 2008). Essas considerações são realizadas apesar de as combinações representarem, em média, um risco menor no desempenho da previsão em comparação com as previsões individuais (HIBON; EVGENIOU, 2005).

Em função disso, o objetivo geral deste artigo é verificar, para previsões de demanda quantitativas, se há diferença entre a acurácia das previsões individuais e suas combinações, através da modelagem das séries industriais do M3-Competition (estudo realizado por Makridakis e Hibon em 2000 que reúne em um banco de dados de domínio público 3003 séries de dados reais). Para tanto serão utilizadas duas técnicas de previsão: a metodologia definida por Box-Jenkins na década de 1970 (modelos ARIMA) e os modelos RNA, apresentados em 1943 por McCulloch e Pitts. A utilização da metodologia Box-Jenkins é justificada pela consolidação e aplicabilidade do método, enquanto que a utilização de RNA que, segundo Ripley (1996), representa uma classe de modelos robustos, ainda é pouco utilizada para a previsão de demandas.

A estrutura do artigo está assim organizada: a primeira seção apresenta esta introdução, as seções seguintes apresentam um referencial teórico sobre os modelos e as combinações de previsões. Na seção 5 é descrito o método utilizado para efetivação do objetivo. Na seção 6 são expostos os resultados obtidos e, na seção final, são explicitadas as conclusões obtidas através deste estudo.

\section{Modelo Box-Jenkins}

Para a análise de modelos paramétricos, uma metodologia bastante utilizada é a abordagem proposta por Box e Jenkins (1976). Essa metodologia consiste no ajuste de modelos autorregressivos integrados de médias móveis, ARIMA ( $p, d, q)$, ao conjunto de dados (MORETTIN; TOLOl, 2006). De acordo com Khashei e Bijari (2010), essa metodologia predomina há muitos anos em várias áreas de previsão. Para a construção do modelo, Box, Jenkins e Reinsel (1994) apresentaram quatro etapas: Especificação, ldentificação, Estimação e Verificação.

Podem ser identificados diferentes modelos através da metodologia de Box-Jenkins, entre os principais estão: autorregressivos de ordem $p$ (AR), médias móveis de ordem $q$ (MA), autorregressivo de médias móveis de ordem $p, q$ (ARMA), os autorregressivos integrados de médias móveis de ordem $p, d, q$ (ARIMA) e os autorregressivos integrados de médias móveis sazonais, de ordem $P, D, Q, p, d, q$, com estação sazonal $s$ (SARIMA).

Após a modelagem de uma série temporal, podem ser calculadas previsões $h$ passos à frente (MORETTIN; TOLOI, 2006). As previsões apresentadas para a série de dados analisados com o modelo ARIMA $(p, d, q)$ podem ser obtidas conforme Equação 1.

$$
\begin{aligned}
& Z_{t+h}=\varphi_{1} Z_{t+h-1}+\ldots+\varphi_{p+d} Z_{t+h-p-d}- \\
& \theta_{1} \varepsilon_{t+h-1}-\ldots-\theta_{q} \varepsilon_{t+h-q}+\varepsilon_{t+h}
\end{aligned}
$$


onde: $\varphi_{1}(B)=1-\varphi_{1} B-\varphi_{2} B^{2}-\ldots-\varphi_{p+d} B^{p+d}$, no qual $B^{n} Z_{t}=Z_{t-n}$

A metodologia Box-Jenkins explora a autocorrelação entre os valores da série em diferentes instantes $t$ sucessivos. Observando os padrões de autocorrelação, em geral é possível identificar um ou vários modelos possíveis para a série de tempo (KHASHEl; BIJARl, 2010). Quando a autocorrelação é observada dentro do período de um ano, por exemplo, considera-se uma estação de sazonalidade $s$ e as séries originais podem ser ajustadas por um modelo ARIMA sazonal (WERNER; RIBEIRO, 2003; MORETTIN; TOLOI, 2006).

A classe de modelos ARIMA sazonal (SARIMA), de ordem $(p, d, q) \times(P, D, Q)$ s é constituída por uma parte não-sazonal ( $p, d, q)$ e outra sazonal (P, D, Q)s. Segundo Chen e Wang (2007), esse é o modelo linear mais popular para a previsão de séries temporais sazonais, tendo apresentado nas últimas três décadas grande sucesso em pesquisas acadêmicas e aplicações industriais. Os modelos SARIMA são definidos conforme a Equação 2 e as previsões obtidas para $h$ passos à frente, por meio dessa classe de modelo, são descritas na Equação 3, que corresponde à solução da equação de diferenças.

$\phi(B) \Phi\left(\mathrm{B}^{\mathrm{s}}\right)\left(1-B^{s}\right)^{D}(1-B)^{d} Z_{t}=\theta(B) \Theta\left(B^{s}\right) \varepsilon_{t}$

$$
\phi(\mathrm{B}) \Phi\left(B^{s}\right)\left(1-B^{s}\right)^{D}(1-B)^{d} \hat{Z}_{t}(h)=0
$$

nas quais:

$$
\Phi\left(B^{s}\right)=1-\Phi_{1} B^{s}-\ldots-\Phi_{P} B^{s P} \quad \text { é o operador }
$$

autorregressivo sazonal de ordem $P$;

$$
\Theta\left(B^{s}\right)=1-\Theta_{1} B^{s}-\ldots-\Theta_{Q} B^{s Q} \text { é o operador }
$$

autorregressivo sazonal de ordem $Q$;

$\left(1-B^{5}\right)^{\mathrm{D}}$ é o operador diferença sazonal, com $D$ indicando o número de diferenças sazonais;

$\left(1-B^{s}\right)^{d}$ é o operador diferença simples, com $d$ indicando o número de diferenças simples;

$$
\theta(\mathrm{B})=1-\theta_{1} B-\ldots-\theta_{p} B^{p} \quad \text { é } \quad \text { operador }
$$

autorregressivo de ordem $p$, estacionário;

$$
\phi(B)=1-\phi_{1} B-\ldots-\phi_{q} B^{q} \text { é o operador }
$$

autorregressivo de ordem $q$;

$\left\{\varepsilon_{t}\right\}_{t \in \mathbb{Z}}$ é um processo de ruído branco gaussiano, ou seja, $\varepsilon_{t} \sim N\left(0, \sigma^{2}\right), \forall t \in \mathbb{Z}$.

\section{Modelo de redes neurais artificiais (RNA)}

Outra forma de se analisar uma série de tempo é por meio do uso de modelos de redes neurais artificiais
(RNA) (HAIR JUNIOR et al., 2005). Mesmo com alguns de seus modelos apresentando suposições quanto às distribuições de probabilidade dos dados, esses são considerados não paramétricos ou de estatística robusta (RIPLEY, 1996). 0 termo robusto se deve ao fato de os modelos de RNA serem capazes de lidar melhor com certas características dos dados, como a não linearidade, do que outros modelos (FLORES, 2009). Além disso, os modelos RNA possuem certa facilidade para analisar sistemas dinâmicos como séries temporais não estacionárias (MÜLLER; REINHARDT; STRICKLAND, 1995; DE WILDE, 1997; HAYKIN, 2001).

De um modo geral, as RNAs possuem uma estrutura que pode ser descrita por quatro grupos: neurônios (nós), tipo de modelo de rede neural, as redes e o aprendizado.

0 neurônio é o principal elemento em uma RNA (MÜLLER; REINHARDT; STRICKLAND, 1995; RIPLEY, 1996; DE WILDE, 1997; HAYKIN, 2001). É assim considerado por executar todos os passos como entradas e saída de dados. No modelo geral de um neurônio são identificados os seguintes elementos: conexões, junção aditiva, função de ativação e o viés ou bias - para mais detalhes consultar Haykin (2001).

Os modelos de RNA podem ser divididos em diferentes classes especiais como, por exemplo, redes de função de base radial e perceptron de múltiplas camadas (MLP). Porém, quanto ao formato, pode ser dividido em três classes gerais, diferenciadas por meio de seu funcionamento, são elas: redes alimentadas adiante com camada única, redes alimentadas adiante com múltiplas camadas e redes recorrentes (MÜLLER; REINHARDT; STRICKLAND, 1995; DE WILDE, 1997; HAYKIN, 2001). Redes neurais alimentadas adiante com múltiplas camadas são referidas como o modelo mais conhecido de RNA (HAYKIN, 2001; ZHANG; BERARDI, 2001; Q1; ZHANG, 2001; AUER; BURGSTEINER; MAASS, 2008). Esse modelo de RNA é considerado por Qi e Zhang (2001) como o mais utilizado. Em tal modelo, a rede apresenta uma ou mais camadas ocultas de neurônios.

0 aumento de capacidade de sinapse oferecido pela camada oculta e a camada de saída possibilita a análise de sistemas complexos, como séries temporais não estacionárias, por exemplo. Como o sinal de cada camada oculta depende da camada imediatamente anterior, isso aumenta a capacidade da rede, o que também aumenta a quantidade de parâmetros do modelo (FLORES, 2009). A configuração da rede neural é um arranjo sequencial que abrange três tipos de camadas, compostas pelos neurônios: de entrada, de saída e oculta.

$\mathrm{Na}$ camada de entrada, os neurônios recebem os dados e realizam a transmissão para a rede neural. 
Ao analisar uma série de tempo podem-se incluir os efeitos temporais como variáveis de entrada. 0 neurônio de saída recebe uma entrada e calcula um valor de saída. No caso de modelos preditivos, esse valor representa a previsão. Para modelos com estruturas mais complexas são empregados neurônios em uma camada oculta. As camadas ocultas e a função de ativação permitem a análise de modelos não lineares (HAIR JUNIOR et al., 2005) e auxiliam a modelagem de comportamentos como tendência e sazonalidade. A Figura 1 apresenta a estrutura de uma rede neural.

\section{Combinação de previsões}

A melhoria do desempenho das previsões de demanda constitui uma busca constante dos previsores em diversos ambientes organizacionais. Com essa finalidade desenvolvem-se diferentes formas de obterem-se previsões. Um desses métodos é conhecido como combinação de previsões (WEBBY; O'CONNOR, 1996).

A combinação de previsões é um método frequentemente utilizado para melhorar a acurácia das previsões (COSTANTINE; PAPPALARDO, 2010). Foi apresentada inicialmente por Bates e Granger (1969) e é considerada, segundo Clemen (1989), um método atraente para realizar previsões. A literatura indica que a combinação linear de previsões comumente é mais acurada que as previsões individuais que a compõem (CLEMEN, 1989; STOCK; WATSON, 2004; MAKRIDAKIS; HIBON, 2000; PATTON; SHEPPARD, 2009; COSTANTINE; PAPPALARDO, 2010).

Após a proposta de combinação apresentada em 1969, surgiram outros estudos propondo diferentes
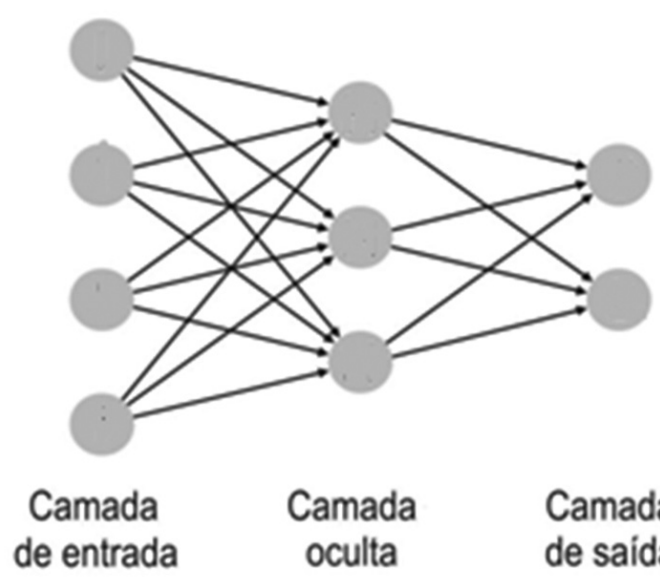

Camada de saída

Figura 1. Rede neural. Fonte: adaptado de Hair Junior et al. (2005). combinações. Em 1974, Newbold e Granger publicaram um estudo comparativo utilizando previsões individuais e suas combinações, obtidas por meio do método apresentado em 1969 e aplicadas a séries econômicas; tal estudo indica um ganho na acurácia quando previsões univariadas foram combinadas. Em 1989, Clemen apresentou uma extensa revisão bibliográfica sobre combinações, composta por 209 artigos. As pressuposições exigidas quanto à utilização dos modelos de combinação foi o tema abordado por Yang (2004).

A obtenção de uma previsão por meio da combinação de outras previsões realizadas com técnicas distintas pode melhorar a acurácia das previsões. Tal afirmação é possível assumindo-se que as técnicas de previsão individuais são oriundas de diferentes abordagens e podem capturar características distintas de cada série (ARMSTRONG, 2001). As previsões que compõem a combinação também apresentam diferentes abordagens. As combinações objetivas aplicadas neste trabalho são o método da variância mínima e o método da média aritmética.

\subsection{Método da variância mínima}

0 método que foi proposto por Bates e Granger (1969) consiste em realizar a combinação linear de duas previsões objetivas. Nesse método, as previsões objetivas devem ser não viesadas e a combinação das previsões é obtida atribuindo-se um peso para cada uma das previsões individuais que serão combinadas. Sua estrutura é apresentada conforme a Equação 4.

$F_{c}=w F_{1}+(1-w) F_{2}$

onde: $w$ é o peso atribuído à previsão e $F_{1}$ e $F_{2}$ são as previsões individuais a serem combinadas.

A estrutura de obtenção dos pesos descritos na Equação 4 é embasada na observação das variâncias dos erros das previsões individuais e na correlação entre os erros de previsão dessas duas previsões individuais, obtidas de forma independente. Para atribuir menor peso às previsões de maior variabilidade, a combinação dessas previsões deve ser calculada utilizando os pesos conforme a Equação 5.

$w=\frac{\sigma_{2}^{2}-\rho \sigma_{1} \sigma_{2}}{\sigma_{1}^{2}+\sigma_{2}^{2}-2 \rho \sigma_{1} \sigma_{2}}$

onde: $\rho$ é o valor da correlação linear entre os erros das previsões obtidas em $F_{1}$ e $F_{2}$ e $\sigma_{1}^{2} e \sigma_{2}^{2}$ correspondem à variância dos erros de previsão de $F_{1}$ e $F_{2}$, respectivamente.

A assumpção de que os erros de previsão obtidos em $F_{1}$ e $F_{2}$ são independentes torna a correlação linear 
( $\rho)$ entre esses erros nula. Considerando-se então a independência desses erros pode-se reescrever a Equação 5: a sua reestruturação é apresentada na Equação 6. Esse formato é conhecido como método da variância mínima simplificado.

$$
w=\frac{\sigma_{2}^{2}}{\sigma_{1}^{2}+\sigma_{2}^{2}}
$$

onde: $\sigma_{1}^{2} e \sigma_{2}^{2}$ correspondem à variância dos erros de previsão de $F_{1}$ e $F_{2}$, respectivamente.

\subsection{Método da média aritmética}

Estudos que comparam o desempenho médio da acurácia de diferentes combinações apresentaram em seus resultados que combinações mais sofisticadas podem não apresentar desempenho superior ao das combinações mais simples (MAKRIDAKIS; WINKLER, 1983; STOCK; WATSON, 2004; KONIG et al., 2005).

0 método da média aritmética de combinação de previsões é considerado um estimador simples e de fácil utilização. Armstrong e Collopy (1998) avaliaram que esse método, para determinados casos, mostrou-se mais acurado que métodos mais elaborados. Além disso, de acordo com Clemen e Winkler (1986), não é necessário o conhecimento prévio da precisão ou do grau de dependência entre as previsões para a sua utilização.

Como apenas previsões acuradas devem compor as combinações, grandes diferenças nos desvios padrão dos erros das previsões individuais não são esperadas. Nesses casos, é razoável pensar que a média simples pode apresentar um desempenho melhor que o obtido com a média ponderada (MENEZES; BUNN; TAYLOR, 2000). A média aritmética é um dos métodos mais populares para combinação de diferentes previsões (FLORES; WHITE, 1989).
A combinação de duas previsões por média aritmética, em sua apresentação, pode ser considerada uma simplificação do método da variância mínima, diferenciando-se por apresentar pesos fixos e iguais para cada previsão individual a ser combinada. 0 método da média aritmética, composto por duas previsões, é apresentado na Equação 7.

$F_{c}=0,5 F_{1}+0,5 F_{2}$

onde: $F_{1}$ e $F_{2}$ são as previsões individuais a serem combinadas.

\section{Método}

0 método a ser utilizado neste trabalho consiste em analisar uma amostra das 334 séries industriais que fazem parte das 3003 séries do M3-Competition (MAKRIDAKIS; HIBON, 2000). Essas séries foram escolhidas por serem dados reais industriais. Delas, foram agrupadas as séries com comportamento de tendência e sazonalidade. Do grupo obtido foram selecionadas 50 séries aleatoriamente, utilizando o critério de amostragem aleatória simples. 0 tamanho da amostra foi obtido considerando-se 95\% de confiança, erro padrão de 10\% e aplicação de um ajuste para populações finitas.

Três diferentes etapas serão seguidas para a análise dos dados: (i) realizar a modelagem individual; (ii) obter as combinações de previsões; e (iii) comparar as medidas de acurácia. A Figura 2 apresenta as etapas de análise de cada série de dados.

Na primeira etapa, a modelagem individual aplicada a cada uma das 50 séries selecionadas, utiliza duas técnicas diferentes para a obtenção da previsão: modelos ARIMA e modelos de RNA.

A metodologia Box-Jenkins aplicada às séries considerou em seus modelos os coeficientes do modelo ARIMA juntamente com os seus coeficientes

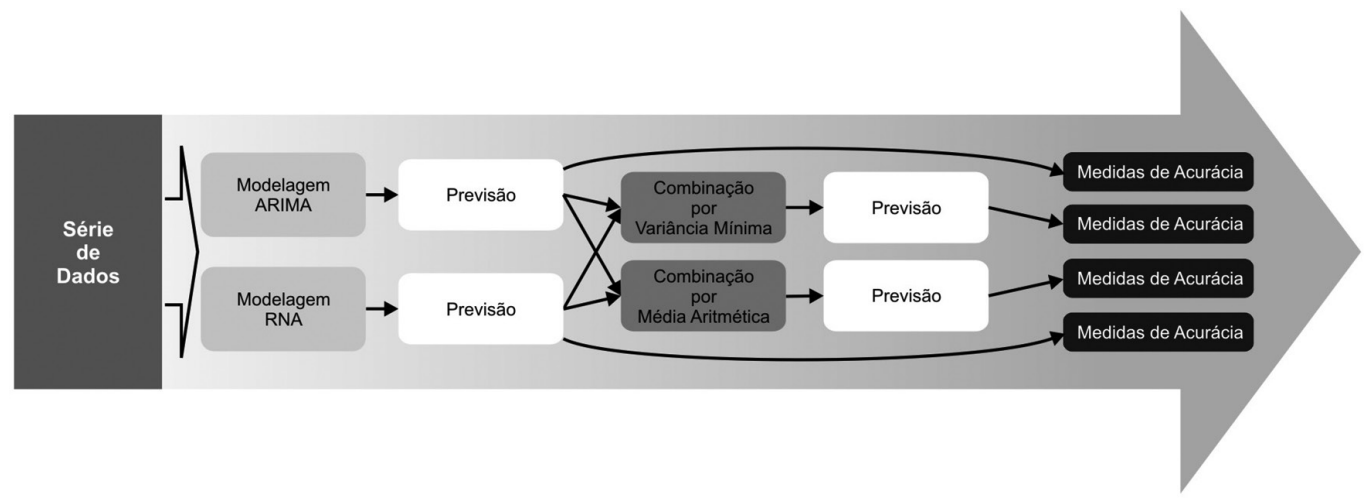

Figura 2. Etapas de análise de cada série de dados. Fonte: elaborado pelos autores. 
de sazonalidade, compondo, portanto, o modelo SARIMA. 0 critério de seleção do modelo utilizado foi o BIC normalizado (do inglês, Normalized Bayesian Information Criterion), após a obtenção das previsões foi realizada a verificação de normalidade dos resíduos com teste de Kolmogorov-Smirnov. Para os modelos de RNA utilizou-se o tipo de rede MLP com aprendizado obtido pelo treinamento supervisionado com retropropagação on-line.

Em cada modelagem realizada (ARIMA e RNA), obtém-se a previsão individual para cada série, o que gera um total de 100 conjuntos de previsões individuais diferentes. Também se calculam três medidas de acurácia para cada modelagem, são elas, MAPE (Mean Absolute Percentual Error), MSE (Mean Square Error), MAE (Mean Absolute Error), perfazendo um total de 300 valores para medidas de acurácia, nessa etapa.

Paliwal e Kumar (2009) apresentam uma revisão de estudos comparativos entre RNAs e técnicas estatísticas de predição. Neste trabalho, verificou-se a utilização das medidas MAPE, MSE e MAE como forma de medir o desempenho das modelagens em diversos artigos. Além disso, de acordo com Goodwin e Lawton (1999), para a comparação de diferentes séries, a medida MAPE é provavelmente uma das mais utilizadas. 0 cálculo das medidas MAPE, MSE e MAE é obtido conforme as Equações 8, 9 e 10, respectivamente.

$\frac{\sum_{t=1}^{n}\left|\left(e_{t} / Y_{t}\right) \times 100\right|}{n}$

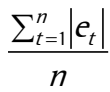

$\frac{\sum_{t=1}^{n} e_{t}^{2}}{n}$

onde: e corresponde ao erro de previsão, $n$ é o número de observações e $Y_{t}$ é o valor observado no tempo $t, t-1,2, \ldots, n$.

Os métodos de combinação de previsões a serem aplicados neste trabalho são: a combinação pelo método da variância mínima simplificado e a combinação pela média aritmética. Cabe ressaltar que para o método de variância mínima foi considerado que as previsões são totalmente independentes e que, portanto, apresentam correlação nula. Em cada combinação se utilizam como previsões individuais as duas previsões obtidas através das modelagens aplicadas na etapa anterior a cada série de dados.

Cada uma das duas combinações, aplicada a cada série de dados, gera um novo grupo de previsões, totalizando então mais 100 previsões diferentes. Após calculam-se três medidas de acurácia para cada método de combinação, são elas: MAPE, MSE e MAE, resultando um total de 300 valores para medidas de acurácia, na segunda etapa.

Por fim, realizam-se as análises estatísticas das medidas de acurácia observadas nas modelagens e combinações. A estrutura das comparações consiste no armazenamento, em 12 vetores, das 300 medidas de acurácia obtidas na primeira etapa com as previsões individuais e das 300 obtidas na segunda etapa com as combinações. A visualização desses vetores é apresentada na Figura 3.

As três medidas de acurácia geradas em cada grupo de análise serão comparadas com as medidas de acurácia correspondentes aos demais blocos, considerando como bloco um método de combinação e/ou uma técnica de previsão.

Outra análise a ser realizada consiste em comparar as frequências de seleção de cada técnica de previsão e método de combinação para cada medida de acurácia, buscando pelas maiores frequências. Tais frequências são obtidas considerando-se o número de vezes em que cada previsão registra a melhor medida de acurácia. Para essa análise também foram gerados vetores nos quais foram armazenados resultados.

0 recurso computacional utilizado para a realização da modelagem dos dados, das combinações das previsões e demais análises estatísticas das medidas de acurácia foi o software SPSS ${ }^{\circledR}$, versão 18.

\section{Análise das combinações}

Para cada uma das 50 séries obtiveram-se as previsões de quatro diferentes formas, duas previsões individuais e duas combinações das previsões individuais. Cada uma delas foi avaliada quanto à sua acuracidade por três medidas distintas: MAPE, MSE, MAE. Uma análise descritiva das medidas de acurácia para cada método de modelagem e técnica de combinação utilizados para a obtenção das previsões é apresentada na Tabela 1.

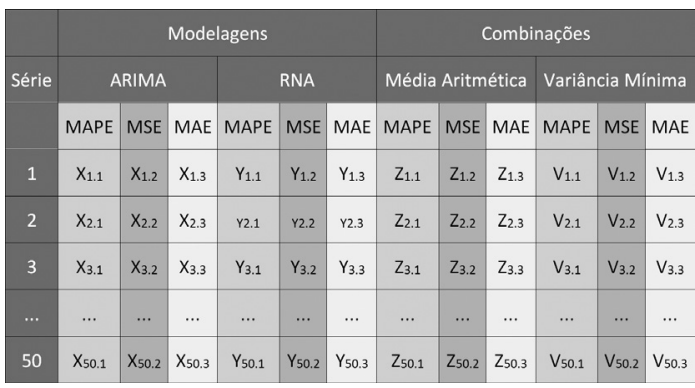

Figura 3. Vetores das medidas de acurácia. Fonte: elaborado pelos autores. 
A análise descritiva mostra que, em média, para as três medidas de acurácia analisadas, os métodos de combinação de previsões apresentaram valores para as medidas de acurácia menores quando comparados às suas previsões individuais. Entre as combinações de previsões, o método da variância mínima foi o que apresentou os melhores resultados.

Uma análise gráfica desaes resultados mostra que as médias encontradas em cada grupo de medida de acurácia apresentam comportamento similar e com alta variabilidade. Os box-plots das medidas de acurácia MAPE, MSE e MAE são apresentados nas Figuras 4, 5 e 6, respectivamente.

Após a verificação de normalidade das variáveis por meio do teste de Kolmogorov-Smirnov e de homogeneidade das variâncias por meio do teste de Levene, procedeu-se com a análise de variâncias (ANOVA) para comparação das médias das medidas de acurácia. Ela mostrou que, ao nível de significância de 5\%, as médias da medida MAPE não diferem entre si, indicando, portanto, que não deve haver diferença entre a acurácia média de cada técnica de previsão e método de combinação ( $p$-valor $=0,183$ ). 0 mesmo ocorreu para as medidas MSE ( $p$-valor $=0,125)$ e MAE ( $p$-valor $=0,136$ ). Salienta-se neste ponto que se tratam de dados reais, sendo que as séries analisadas apresentam variabilidade bastante diversificada.

Todavia, o interesse dos previsores não está na média de medida de acurácia de diferentes séries mas, sim, de forma pontual, na previsão mais acurada para a sua série histórica de dados. Buscando qual técnica ou método realiza a melhor previsão, identificou-se a frequência da técnica ou método mais acurado para cada série de dados, por medida de acurácia.
Em uma análise das frequências de seleção das técnicas de previsão individual, a técnica RNA apresentou maior frequência para as medidas de acurácia MAPE (80\%), MSE (84\%) e MAE (78\%). Esse resultado indica que a modelagem realizada por essa técnica apresentou desempenho superior quanto à sua acurácia quando comparada à modelagem obtida por meio da técnica de previsão ARIMA. A Tabela 2 apresenta as frequências e os percentuais relativos às medidas de acurácia.

A Tabela 3 apresenta as frequências e os percentuais relativos às medidas de acurácia de acordo com cada técnica e método de previsão analisado. A combinação por variância mínima apresentou frequência maior para as medidas de acurácia MAPE (80\%), MSE $(80 \%)$ e MAE (78\%), indicando que esse é o método mais acurado. A técnica de previsão individual RNA e o método de combinação por média aritmética

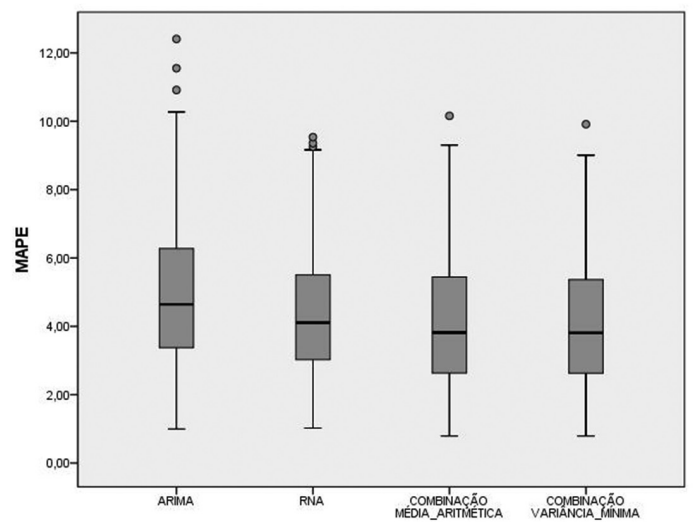

Figura 4. Box-plot para as medidas de acurácia MAPE.

Tabela 1. Análise descritiva das medidas de acurácia das 50 séries analisadas.

\begin{tabular}{|c|c|c|c|c|}
\hline & \multicolumn{4}{|c|}{ MAPE } \\
\hline & Média & Desvio padrão & Mínimo & Máximo \\
\hline ARIMA & 5,16 & 2,75 & 1,00 & 12,41 \\
\hline$R N A$ & 4,60 & 2,27 & 1,03 & 9,54 \\
\hline COMB. MÉDIA ARITMÉTICA & 4,28 & 2,28 & 0,79 & 10,16 \\
\hline \multirow[t]{3}{*}{ COMB. VARIÂNCIA MÍNIMA } & 4,22 & 2,25 & 0,79 & 9,91 \\
\hline & \multicolumn{4}{|c|}{ MSE } \\
\hline & Média & Desvio padrão & Mínimo & Máximo \\
\hline ARIMA & $127.639,92$ & $123.613,31$ & $9.837,27$ & $478.617,73$ \\
\hline$R N A$ & $98.634,49$ & $91.808,41$ & $6.733,97$ & $364.002,61$ \\
\hline COMB. MÉDIA ARITMÉTICA & $88.171,72$ & $86.703,69$ & $6.128,42$ & $352.060,27$ \\
\hline \multirow[t]{3}{*}{ COMB. VARIÂNCIA MÍNIMA } & $85.657,70$ & $84.124,08$ & $6.139,00$ & $338.284,80$ \\
\hline & \multicolumn{4}{|c|}{ MAE } \\
\hline & Média & Desvio padrão & Mínimo & Máximo \\
\hline$A R I M A$ & 246,39 & 126,61 & 76,81 & 562,33 \\
\hline$R N A$ & 218,31 & 101,60 & 62,19 & 457,15 \\
\hline COMB. MÉDIA ARITMÉTICA & 203,56 & 102,42 & 61,53 & 468,02 \\
\hline COMB. VARIÂNCIA MÍNIMA & 200,50 & 100,83 & 61,51 & 456,37 \\
\hline
\end{tabular}




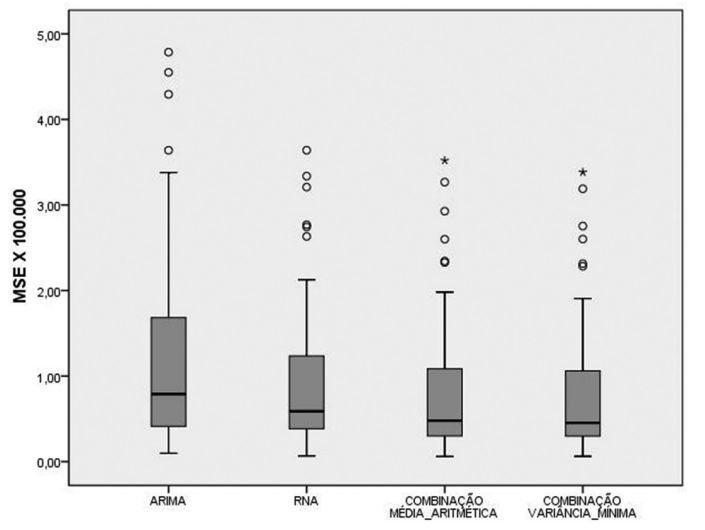

Figura 5. Box-plot para as medidas de acurácia MSE.

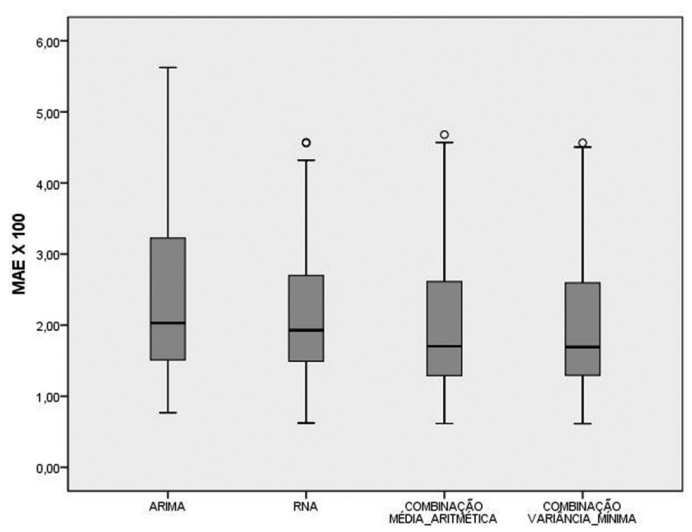

Figura 6. Box-plot para as medidas de acurácia MAE.

apresentaram a mesma frequência para as medidas de acurácia MAPE (10\%) e MSE (10\%). A técnica de previsão individual ARIMA não apresentou melhor acurácia para nenhuma das séries analisadas.

As medidas de acurácia utilizadas apresentaram comportamento uniforme para a seleção da melhor técnica de previsão ou método de combinação. 0 método de combinação por variância mínima foi selecionado como mais preciso pelas três medidas de acurácia simultaneamente para 74\% das séries estudadas. Considerando a totalidade das séries modeladas, a escolha da melhor técnica ou método de previsão foi unânime entre as medidas MAPE, MSE e MAE para $88 \%$ delas, para $12 \%$ das séries, a seleção de melhor acuracidade foi obtida por duas ou apenas uma das medidas. As frequências e os percentuais significativos são apresentados na Tabela 4. 0 percentual de unanimidade encontrado corrobora as afirmações supracitadas.

\section{Conclusões}

0 desenvolvimento e aprimoramento de técnicas aplicadas à gestão da produção representam para
Tabela 2. Frequências e percentuais relativos a medidas de acurácia de cada técnica de previsão.

\begin{tabular}{lccc}
\hline & MAPE & MSE & MAE \\
\hline \multirow{2}{*}{ ARIMA } & 10 & 8 & 11 \\
& $20,0 \%$ & $16,0 \%$ & $22,0 \%$ \\
\multirow{2}{*}{$R N A$} & 40 & 42 & 39 \\
\multirow{2}{*}{ Total } & $80,0 \%$ & $84,0 \%$ & $78,0 \%$ \\
& 50 & 50 & 50 \\
& $100,0 \%$ & $100,0 \%$ & $100,0 \%$ \\
\hline
\end{tabular}

Tabela 3. Frequências e percentuais relativos às medidas de acurácia das técnicas de previsão e métodos de combinação.

\begin{tabular}{lccc}
\hline & MAPE & MSE & MAE \\
\hline \multirow{2}{*}{ ARIMA } & 0 & 0 & 0 \\
& $0,0 \%$ & $0,0 \%$ & $0,0 \%$ \\
RNA & 5 & 5 & 5 \\
COMB. MÉDIA & $10,0 \%$ & $10,0 \%$ & $10,0 \%$ \\
ARITMÉTICA & 5 & 5 & 6 \\
COMB. VARIÂNCIA & $10,0 \%$ & $10,0 \%$ & $12,0 \%$ \\
MÍNIMA & 40 & 40 & 39 \\
\multirow{2}{*}{ Total } & $80,0 \%$ & $80,0 \%$ & $78,0 \%$ \\
& 50 & 50 & 50 \\
& $100,0 \%$ & $100,0 \%$ & $100,0 \%$ \\
\hline
\end{tabular}

Tabela 4. Frequências e percentuais relativos à unanimidade nas escolhas pela técnica ou método de previsão mais acurado.

\begin{tabular}{lcc}
\hline & \multicolumn{2}{c}{$\begin{array}{c}\text { Escolha pelas medidas MAPE, } \\
\text { MSE e MAE }\end{array}$} \\
\cline { 2 - 3 } & Séries & Percentual (\%) \\
\hline ARIMA & 0 & 0 \\
$R N A$ & 4 & 8 \\
COMB. MÉDIA ARITMÉTICA & 3 & 6 \\
COMB. VARIÂNCIA MÍNIMA & 37 & 74 \\
Total & 44 & 88 \\
\hline
\end{tabular}

as empresas uma possibilidade de reduzir custos e aumentar a qualidade dos produtos. Prever adequadamente a demanda do mercado está diretamente ligado a fatores de redução nos custos, de dimensionamento da produção e do estoque. Em função disso, buscou-se verificar, para previsões de demanda quantitativas, se há diferenças entre a acurácia das previsões individuais e suas combinações.

Neste estudo foram utilizadas séries industriais reais, com comportamento de tendência e sazonalidade. Para a obtenção das previsões foram utilizadas as técnicas ARIMA e RNA, que são métodos reconhecidamente robustos para realizar previsões quantitativas. As combinações das previsões individuais foram realizadas por meio dos métodos da média aritmética e variância mínima simplificada - para este último método, as previsões foram consideradas independentes, portanto, com correlação nula. As medidas de acurácia MAPE, MSE e MAE foram utilizadas para investigar qual técnica de previsão ou método de combinação são mais indicados.

No primeiro resultado deste estudo, a ANOVA mostra que, para as 50 séries reais utilizadas e considerando um nível de significância de 5\%, não 
há diferença significativa entre as médias das medidas de acurácia das técnicas de previsão individualmente e as de suas combinações. Tal resultado pode ser atribuído à variabilidade das séries.

Como o interesse dos previsores está na identificação de qual técnica de previsão ou método de combinação fornece as melhores medidas de acurácia, foram investigadas as frequências nas quais elas ocorrem. A análise da frequência das técnicas de previsão individualmente mostra que em aproximadamente $80 \%$ dos casos a técnica de RNA foi mais acurada que a técnica ARIMA. Uma segunda análise das frequências foi realizada considerando juntamente com as técnicas de previsão, individualmente, os métodos de combinação de previsões. Nesse caso o método de combinação por variância mínima simplificada apresentou os melhores resultados em relação às medidas de acurácia, com aproximadamente $80 \%$ das frequências. Ressalta-se nesse resultado que em $88 \%$ dos casos as medidas de acurácia propiciaram unanimidade de escolha.

0 indicativo dos resultados apresentados neste estudo é que a combinação de previsões pelo método da variância mínima simplificado obteve as melhores previsões. Portanto, a utilização da variância na composição da previsão combinada não deve ser ignorada pelos previsores.

Há ainda outras questões a serem investigadas em relação a técnicas de previsão e métodos de combinação. A utilização de séries reais contemplando outros comportamentos não apresentados neste estudo, bem como a utilização de diferentes técnicas de modelagem e diferentes métodos de combinação que utilizem correlação entre os erros na composição dos pesos compõem uma gama de opções para a realização de trabalhos futuros.

\section{Referências}

ABRAHAM, B.; LEDOLTER, J. Statistical Methods for Forecasting. New York: John Wiley \& Sons, 2005.

ANDERSON-CONNELL, L. J.; ULRICH, P. V.; BRANNON, E. L. A consumer-driven model for mass customization in apparel market. Journal of Fashion Marketing and Management, v. 6, n. 3, p. 240-258, 2002. http://dx.doi. org/10.1108/13612020210441346

ANDRAWIS, R. R.; ATIYA, A. F.; EL-SHISHINY, H. Combination of long term and short term forecasts, with application to tourism demand forecasting. International Journal of Forecasting, v. 27, n. 3, p. 870-886, 2011. http://dx.doi. org/10.1016/j.ijforecast.2010.05.019

ARMSTRONG, J. S. Principles of forecasting: A handbook for researchers and practitioners. Kluwer Academic Publishers. 2001. http://dx.doi.org/10.1007/978-0-30647630-3

ARMSTRONG, J. S.; COLLOPY, F. Integration of Statistical Methods and Judgments of Time Series Forecasting: Principles for Empirical Research. In: WRIGHT, G.; G00DWIN, P. Forecasting with Judgment. Wiley \& Sons, 1998.
AUER, P.; BURGSTEINER, H.; MAASS, W. A learning rule for very simple universal approximators consisting of a single layer of perceptrons. Neural Networks, v. 21, p. 786-795, 2008. PMid:18249524. http://dx.doi. org/10.1016/j.neunet.2007.12.036

BATES, J. M.; GRANGER, C. W. J. The combination of forecasts. Operational Research Quarterly, v. 20, n. 4, p. 451-468, 1969. http://dx.doi.org/10.1057/ jors. 1969.103

BOX, G. E. P.; JENKINS, G. M. Time series analysis. San Francisco: Holden-Day, 1976.

BOX, G. E. P.; JENKINS, G. M.; REINSEL, G. C. Time Series Analysis, Forecasting and Control. 3rd ed. Englewood Clifs: Prentice Hall, 1994. 598 p.

CHEN, K. Y.; WANG, C. H. A hybrid SARIMA and support vector machines in forecasting the production values of the machinery industry in Taiwan. Expert Systems with Applications, v. 32, n. 1, p. 254-264, 2007. http://dx.doi. org/10.1016/j.eswa.2005.11.027

CLARK, K. B.; FUJIMOTO, T. Product development performance: strategy, organization and management in the world auto industry. Boston: Harvard Business School Press, 1991.

CLARK, K. B.; WHEELWRIGTH, S. C. Managing New Product and Process Development: text and cases. New York: The Free Press, 1993. 896 p.

CLEMEN, R. T. Combining forecasts: A review and annotated bibliography. International journal of forecasting, v. 5, p. 559-583, 1989. http://dx.doi.org/10.1016/01692070(89)90012-5

CLEMEN, R. T.; WINKLER, R. L. Combining economic forecasts. Journal of Business and Economic Estatistics, v. 4, p. 39-46, 1986.

COSTANTINE, C.; PAPPALARDO, C. A hierarchical procedure for combination of forecasts. International journal of forecasting, v. 26, p. 725-743, 2010. http://dx.doi. org/10.1016/j.jforecast.2009.09.006

DE WILDE, P. Neural networks models: theory and projects. 2. ed. New York: Springer-Verlag, 1997. 174 p.

FLORES, B. E.; WHITE, E. M. Combining forecasts: why, when and how. Journal of Business Forecasting Methods \& Systems, v. 8, n. 3, p. 2-5, 1989.

FLORES, J. H. F. Comparação de modelos $M L P / R N A$ e modelos Box-Jenkins em séries temporais não lineares. 2009. Dissertação (Mestrado em Engenharia de Produção)-Universidade Federal do Rio Grande do Sul, Porto Alegre, 2009.

GARCIA, E. et al. Gestão de Estoques: Otimizando a logística e a cadeia de suprimentos. Rio de Janeiro: E-Papers Serviços Editoriais, 2006. $144 \mathrm{p}$.

GILMORE, J. H.; PINE II, J. B. Markets of one: creating customer-unique value through mass customization. Boston: Harvard Business School Press, 2000.

GOODWIN, P.; LAWTON, R. On the asymmetry of the symmetric MAPE. International journal of forecasting, v. 15 , p. 405-408, 1999. http://dx.doi.org/10.1016/ S0169-2070(99)00007-2

HAIR JUNIOR, J. F. et al. Análise multivariada de dados. 5. ed. Porto Alegre: Bookman, 2005. 593 p.

HAYKIN, S. Redes neurais: princípios e prática. 2. ed. Porto Alegre: Bookman, 2001. 900 p.

HIBON, M.; EVGENIOU, T. To combine or not to combine: selecting among forecasts and their combinations. International Journal of Forecasting, v. 21, p. 15-24, 2005. http://dx.doi.org/10.1016/j.ijforecast.2004.05.002 
HOLLAUER, G.; ISSLER, J. V.; NOTINI, H. H. Prevendo o crescimento da produção industrial usando um número limitado de combinações de previsões. Economia Aplicada, v. 12, n. 2, p. 177-198, 2008. http://dx.doi. org/10.1590/S1413-80502008000200001

KHASHEI, M.; BIJARI, M. An artificial neural network (p, d, q) model for timeseries forecasting. Expert Systems with Applications, v. 37, p. 479-489, 2010. http://dx.doi. org/10.1016/j.eswa.2009.05.044

KONIG, A. J. et al. The M3-Competition: Statistical tests of the results. International Journal of Forecasting, v. 21, p. 397-409, 2005. http://dx.doi.org/10.1016/j. ijforecast.2004.10.003

MAKRIDAKIS, S. G.; HIBON, M. The M3-Competition: results, conclusions and implications. International Journal of Forecasting, v. 16, p. 451-476, 2000. http://dx.doi. org/10.1016/S0169-2070(00)00057-1

MAKRIDAKIS, S. G.; WHEELWRIGHT, S. C.; HYNDMAN, R. J. Forecasting: methods and applications. 3. ed. Wiley, 1998. $642 \mathrm{p}$.

MAKRIDAKIS, S. G.; WINKLER, R. L. Averages of Forecasts: Some empirical results. Menagement Science, v. 29, p. 987-996, 1983. http://dx.doi.org/10.1287/ mnsc.29.9.987

MENEZES, L. M.; BUNN, D. W.; TAYLOR, J. W. Review of guidelines for the use combined forecast. European Journal of Operational Research, v. 120, p. 190-204, 2000. http://dx.doi.org/10.1016/S0377-2217(98)00380-4

MORETTIN, P. A.; TOLOI, C. M. C. Análise de séries temporais. 2 ed. rev. ampl. São Pulo: Edgard Blücher, 2006. 538 p.

MÜLLER, B.; REINHARDT, J.; STRICKLAND, M. T. Neural networks: an introduction. 2. ed. New York: SpringerVerlag, 1995. $330 \mathrm{p}$.

NEWBOLD, P.; GRANGER, C. W. J. Experience with forecasting univariate time series and the combination of forecasts. Journal of the Royal Statistical Society. Series A (General), v. 137, n. 2, p. 131-165, 1974. http://dx.doi. $\operatorname{org} / 10.2307 / 2344546$

PATTON, A. J.; SHEPPARD, K. Optimal combinations of realised volatility estimators. International Journal of Forecasting, v. 25, 2009, p. 218-238. http://dx.doi.org/10.1016/j. ijforecast.2009.01.011

Ql, M.; ZHANG, G. P. An investigation of model section criteria for neural network time series forecasting. European
Journal of Operational Research, v. 132, p. 666-680, 2001. http://dx.doi.org/10.1016/S0377-2217(00)00171-5

RIPLEY, B. D. Pattern recognition and neural networks. Cambridge: Cambridge University Press, 1996. 415 p.

PALIWAL, M.; KUMAR, U. A. Neural networks and statistical techniques: A review of applications. Expert Systems with Applications, v. 36, p. 2-17, 2009. http://dx.doi. $\operatorname{org} / 10.1016 / j$.eswa.2007.10.005

SLACK, N. et al. Administração da Produção. 2. ed. São Paulo: Atlas, 2007.

STOCK, J. H.; WATSON, M. W. Combination forecasts of output growth in a seven-country data set. Journal of Forecasting, v. 23, p. 405-430, 2004. http://dx.doi. org/10.1002/for.928

TIMMERMANN, A. Forecast Combinations. In: ELLIOTT, G.; GRANGER, C. W. J.; TIMMERMANN, A. Handbook of Economic Forecasting. San Diego: North-Holland, 2006. v. 1.

WEBBY, R.; O'CONNOR, M. Judgemental and statistical time series forecasting: a review of the literature. International Journal of Forecast, v. 12, p. 91-118, 1996. http://dx.doi. org/10.1016/0169-2070(95)00644-3

WERNER, L. Um modelo composto para realizar previsão de demanda através da integração da combinação e de previsões e ajuste baseado na opinião. 2005. Tese (Doutorado)-Universidade Federal do Rio Grande do Sul, Porto Alegre, 2005.

WERNER, L.; RIBEIRO, J. L. D. Previsão de demanda: uma aplicação dos modelos Box-Jenkins na área de assistência técnica de computadores pessoais. Gestão e Produção, v. 10, n. 1, p. 47-67, 2003. http://dx.doi.org/10.1590/ S0104-530X2003000100005

WONG, K. K. F. et al. Tourism forecasting: To combine or not to combine?. Tourism management, v. 28, p. 1068-1078, 2007. http://dx.doi.org/10.1016/j. tourman.2006.08.003

YANG, Y. Combining forecasts procedures: Some theoretical results. Econometric Theory, v. 20, p. 176-190, 2004. http://dx.doi.org/10.1017/S0266466604201086

ZHANG, G. P.; BERARDI, V. L. Time series forecasting with neural network ensembles: an application for exchange rate prediction. Journal of Operational Research Society, v. 52, p. 652-664, 2001. http://dx.doi.org/10.1057/ palgrave.jors. 2601133

\title{
Comparison of individual forecasts and their combinations: a study with industrial series
}

\begin{abstract}
Technological development has increased the necessity for more accurate predictions that stimulate the application and comparison of modeling techniques and methods of combination. Historically, researchers have believed that combining forecasts from different techniques improves the forecasts, but some studies question whether combining is really the best option. This paper aims to verify whether there is a difference between the accuracy of individual forecasts and that of their combinations by modeling real industrial prediction series. The Box-Jenkins methodology and ANN modeling were used for individual forecasting, whereas the simplified minimum variance and mean arithmetic methods were used for forecast combinations. The performance of the predictions was evaluated by MAPE (Mean Absolute Percentual Error), MSE (Mean Square Error) and MAE (Mean Absolute Error). As the main result, we highlight the predominant frequency at which the predictions obtained by the minimum variance method show superior performance compared to other forecasts.
\end{abstract}

\section{Keywords}

Forecasting. Accuracy. Combining. 